Supplementary Material for:

\title{
Bond or Cage effect: How Nitrophorins transport and release Nitric Oxide
}

Marcelo A. Marti, Mariano Camilo Gonzalez Lebrero, Adrian Roitberg and Dario Estrin

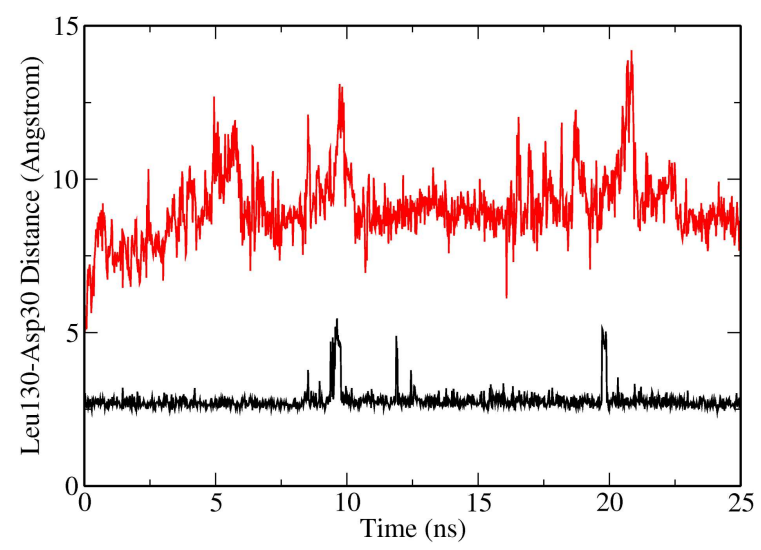

Figure SM1 Leu130 carbonyl oxygen to Asp30 carboxylate oxygen vs time plot. Black line low $\mathrm{pH}$ run, red line high $\mathrm{pH}$ run.

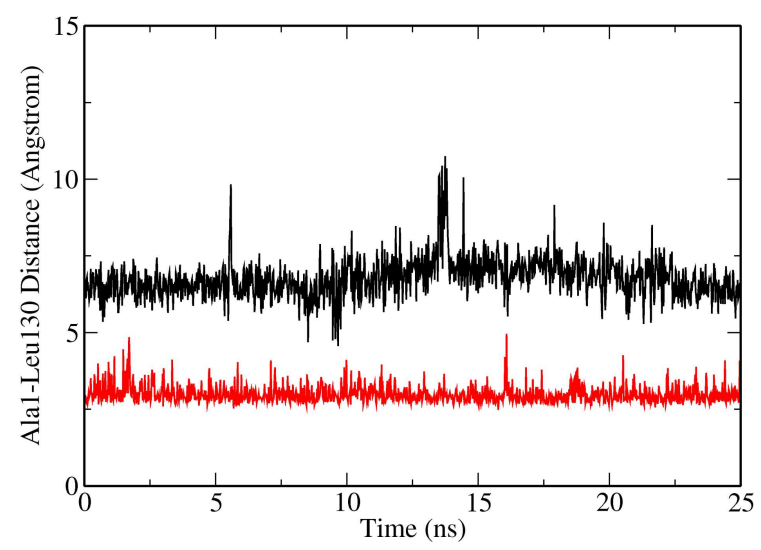

Figure SM2 Leu130 carbonyl oxygen to Ala1 $\mathrm{NH}_{3}$ vs time plot. Black line low $\mathrm{pH}$ run, red line high $\mathrm{pH}$ run.
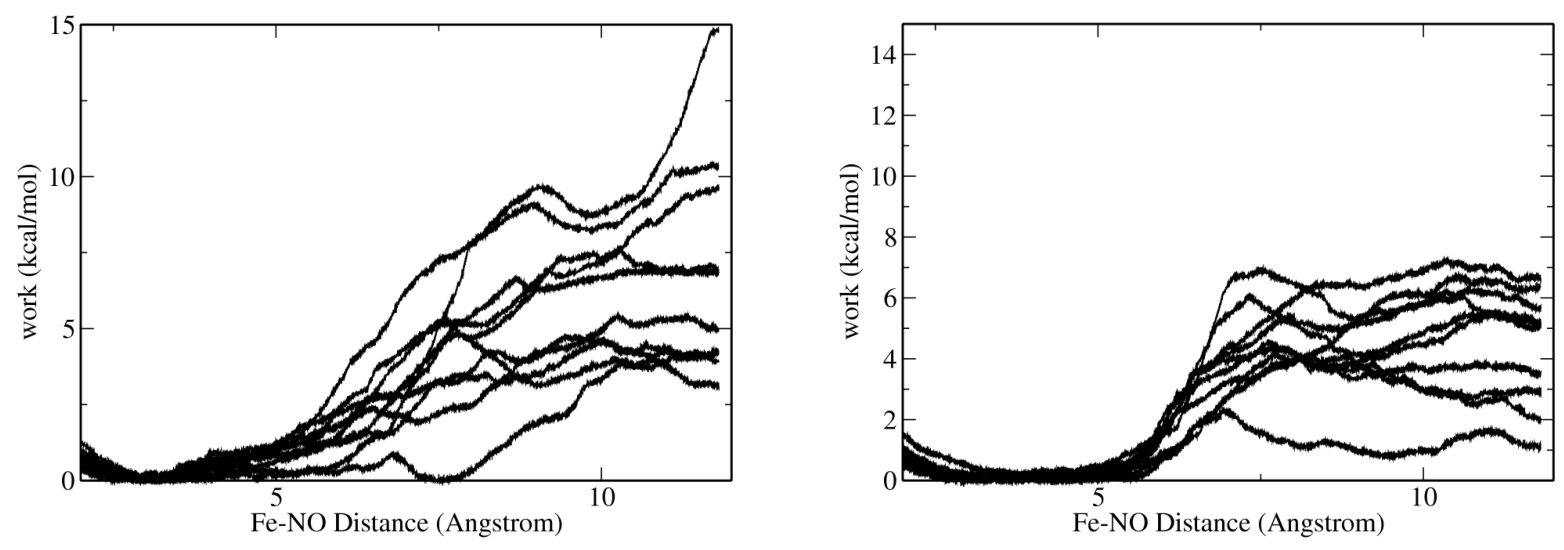
Figure SM3 Work vs RC vales for the MSMD runs, at the high $\mathrm{pH}$ condition. Each panel corresponds to a set of10 runs

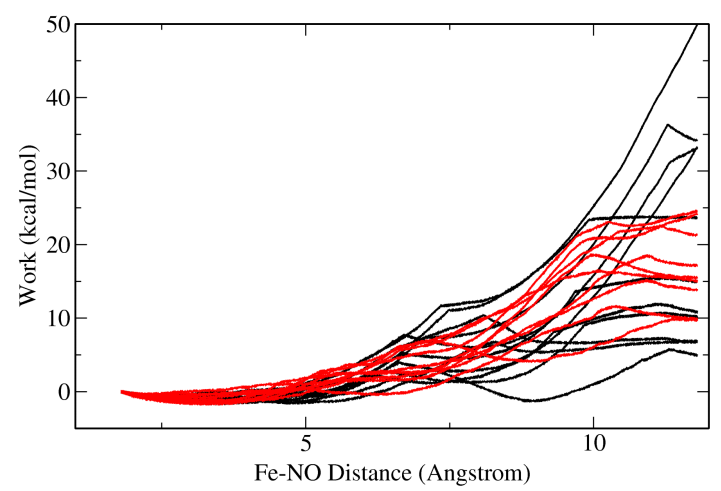

Figure SM4 Work vs RC vales for the 20 SMD runs, at the low $\mathrm{pH}$ condition, Black line: runs where the NO migrates further inside the protein. Red line: runs where the NO escapes the protein.

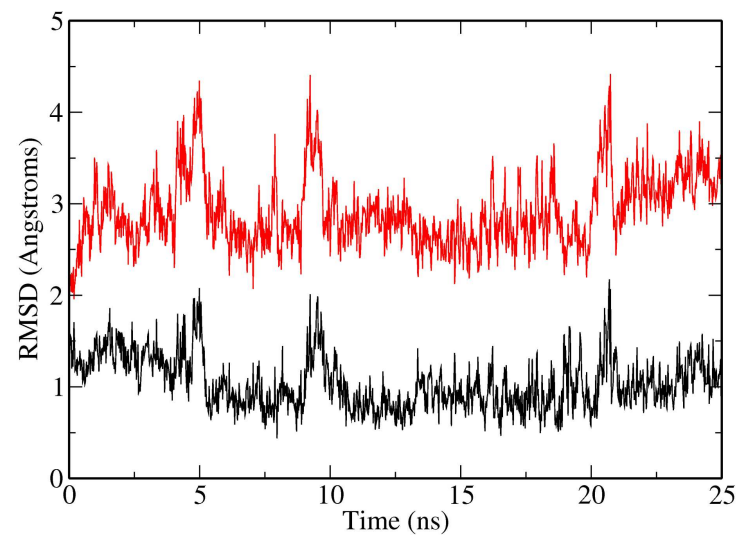

Figure SM5 AB and CG loops (Residues 28 to 40 and 124 to 132) Ca-RMSD along the high pH NP4-NO MD run using as references the high and low $\mathrm{pH}$ average structures, depicted in black and red lines, respectively. 